\title{
GENETIC TREND IN SELECTION FOR LITTER WEIGHT IN TWO MATERNAL LINES OF RABBITS IN EGYPT
}

\author{
Abou Khadiga G.*, Youssef Y. M. K..", Saleh K.†, Nofal R. Y.†, Baselga M.* \\ *Animal Production Research Institute. Nadi El-Sead St. Doki. Giza. Egypt. \\ ${ }^{\dagger}$ Poultry Production Department, Faculty of Agriculture. Kafrelsheikh University. KafRelsheIKH. Egypt. \\ *Instituto de Ciencia y Tecnología Animal. Universidad Politécnica de Valencia. Camino de Vera s/n. 46022 VALENCIA. Spain.
}

\begin{abstract}
AвSTRACt: An analysis was carried out to evaluate the results of the selection program of a new synthetic maternal line of Egyptian APRI rabbits and the Spanish V line. The selection criterion was litter weaning weight in both lines based on Best Linear Unbiased Prediction (BLUP) estimations under a repeatability animal model. The studied traits were: litter birth weight, litter weaning weight (at $28 \mathrm{~d}$ ) and pre-weaning litter gain. Heritability estimates were generally low (0.09 to $0.11)$ and comparable in both lines. Low to moderate estimates of repeatability were observed for all studied traits $(0.15$ to 0.31$)$. Estimates of genetic correlations were high $(0.77$ to 0.97$)$, while permanent environmental effects correlations were mostly lower than genetic correlations $(0.47$ to 0.87$)$. The genetic trends were also estimated using mixed model methodology and were significant and comparable (34.2 and $32.5 \mathrm{~g}$ ) for the selected trait (litter weaning weight) in APRI and $\mathrm{V}$ lines, respectively. Furthermore, correlated genetic trends were significant $(P<0.05)$ for other litter weight traits. These results indicate that the current selection program has been effective in achieving genetic improvement in litter weight traits.
\end{abstract}

Key Words: rabbits, lines, selection, mixed model, litter weight.

\section{INTRODUCTION}

Litter weight and mean kit weight at different ages are important traits in commercial farms (Abou Khadiga, 2004). Litter weaning weight is a particularly important composite trait of the doe because it is affected by litter size, kit viability, the doe's mothering and milking ability and growth response of the litter (Lukefahr and Hamilton, 1997). Traits related with doe productivity, such as litter sizes and weights and milk production are considered selection objectives in developing maternal rabbit lines (Estany et al., 1989; Gómez et al., 1996; Rochambeau et al., 1998; Baselga, 2004). Selection for litter weaning weight could, in theory, be more interesting than selection for litter size at birth or weaning, since this type of selection allows litter size and other traits such as milk production to be considered. Nevertheless, few experiments considering litter weaning weight as a main selection criterion in rabbit lines have been reported (Gómez et al., 2000; Moura et al., 2001; Salaun et al., 2001; Khalil et al., 2005; Youssef et al., 2008a).

Correspondence: G. Abou Khadiga, abokhadiga@yahoo.com

Received September 2009 - Accepted January 2010 
The objective of this study was to estimate the genetic trends for litter weight traits in two maternal lines of rabbits selected for litter weight at weaning in Egypt.

\section{MATERIALS AND METHODS}

\section{Animals and studied traits}

Animals belonging to two maternal lines of rabbits, the APRI and V lines were involved in this experiment. The APRI line was founded by mating Baladi Red (BR) bucks to $\mathrm{V}$ line does, obtaining the $\mathrm{F}_{1}, \mathrm{~F}_{2}$ and then $\mathrm{F}_{3}$, starting the selection at this generation (Youssef et al., 2008a). The records of $\mathrm{F}_{1}$ and $\mathrm{F}_{2}$ were not considered in the subsequent analyses, since they were far from the genetic equilibrium. $\mathrm{F}_{3}$ was chosen as the starting point as a compromise between approximation to equilibrium and applicability.

The APRI line is reared in Sakha experimental rabbitry, Animal Production Research Institute (APRI), Agricultural Research Center, Ministry of Agriculture, Egypt. The V line was founded in 1981 in Spain (Polytechnic University of Valencia) as a synthetic line by crossing the progeny of four specialized maternal lines that had been selected to increase litter size at weaning (Estany et al., 1989). A replicate of the V lines was established in 2002 in Sakha and the selection criterion was changed to litter weaning weight as in the APRI line (Youssef et al., 2008a). The data used in this study were taken from the collected records of APRI and V line rabbits during the period from September 2003 to May 2008. They correspond to a total of 3306 litters (1400 for APRI and 1906 for V line) from six generations, the traits recorded being: litter birth weight (LBW), litter weaning weight (LWW, at $28 \mathrm{~d}$ ) and pre-weaning litter gain (PLG). The distribution of animals in the set of both lines is shown in Table1.

\section{Selection program}

Selection in both lines started after three generations of random mating to approximate genetic equilibrium in the new formed APRI line. LWW was the selection criterion in both lines. The genetic evaluation was carried out using BLUP (Best Linear Unbiased Prediction) under a repeatability animal model (Quaas, 1984). Values of 0.10 and 0.16 were considered for heritability and repeatability, respectively. The females of the next generation were selected from the progeny of $31-36 \%$ of the best evaluated matings based on the average of the predicted breeding values of their parents, while the males were selected within sire. At least one male from the progeny of each sire was selected in order to diminish inbreeding depression throughout the generations.

\section{Genetic parameters and genetic trend}

As it was not possible to maintain control lines, mixed model methodology (Henderson, 1973) was used to estimate the genetic trend and as selection applied for litter weaning weight, this trait was included in all analyses in order to avoid biased estimates due to selection (Sorensen and Johanson, 1992). The first step was to define the mixed model to analyze the data, get the Restricted Maximum Likelihood (REML) estimates of the variance and covariance components and with these estimates obtain the prediction of the additive values of all animals. The averages of the predicted additive values in each generation were

Table 1: Total number of bucks, does, sires, dams, litters and minimal number of does per generation (M).

\begin{tabular}{lcccccc}
\hline Line & Bucks & Does & Sires & Dams & Litters & M \\
\hline APRI & 184 & 428 & 110 & 120 & 1400 & 75 \\
V & 237 & 560 & 211 & 198 & 1906 & 77 \\
\hline
\end{tabular}


regressed on generation number to estimate the genetic trend. Under several assumptions - the complete relationship matrix should be known, as well as the variance components before selection - these averages are unbiased estimates of the genetic means (Sorensen and Kennedy, 1984).

The following repeatability animal model in matrix notation was used:

$$
y=X b+Z a+Z p+e
$$

where, $y$ is the vector of observations; $b$ is the vector of fixed effects of year-season (20 levels) and physiological state of doe at mating (3 levels), taking into account if the doe at mating was nulliparous, was lactating the previous litter or was not lactating; a is the vector of additive genetic effects of animal; $p$ is the vector of the non-additive genetic plus permanent environmental effects of the doe that affect all its parities, which hereafter will be called permanent environmental effects; and e is a vector of residual random effects. The matrix $\mathrm{X}$ is the incidence matrix for the fixed effects and $\mathrm{Z}$ is the incidence matrix relating observations to animals. Data of summer and spring seasons were merged in some generations due to lack of summer data.

REML (co)variance components were estimated by fitting series of multivariate animal models (allowing to estimate correlations among non selected-for traits) using WOMBAT software (Meyer, 2006).

\section{RESULTS AND DISCUSSION}

Only the results directly concerned with the response to selection are presented. Some effects factored into the models, such as year-season or the physiological state of the doe at mating are not reported, but their estimates were within the range of those found in the literature.

Descriptive statistics of the complete set of data for litter weight traits are presented in Table 2. The present results were in the range of reviewed estimates (Abou Khadiga, 2004; Costa et al., 2004; ElDeghadi, 2005; Al-Saef et al., 2008; Youssef et al., 2008b).

\section{Genetic parameters}

Heritability estimates of all traits were generally low and similar in both lines with ranges of 0.09 to 0.11 in APRI and 0.09 to 0.10 in V line (Table 3). Similar results (around 0.1) were reported by several authors (Rastogi et al., 2000; Costa et al., 2004; El-Deghadi, 2005; Iraqi et al., 2006; Gad 2007).

Estimates of the ratio of the variance of permanent environmental effects to the phenotypic variance $\left(\mathrm{p}^{2}\right)$ tended to be lower than $\mathrm{h} 2$ for most traits, except for LBW where the value of $\mathrm{p}^{2}$ was twice higher than $\mathrm{h}^{2}$ in both lines. This could be devised from the estimates of repeatability (r) for all traits in both lines (Table 3). The pattern of $\mathrm{p}^{2}$ values was very similar in both lines and ranged from 0.06 to 0.21 . The higher

Table 2: Descriptive statistics of the experiment. Number of records $(N)$, mean $(\mu)$, standard deviation $(\sigma)$ and range for litter weight $(\mathrm{g})$ traits.

\begin{tabular}{lccc}
\hline & LBW & LWW & PLG \\
\cline { 2 - 4 } $\mathrm{N}$ & 3306 & 3096 & 3096 \\
$\mu$ & 472 & 3218 & 2746 \\
$\sigma$ & 85 & 626 & 597 \\
Range & $80-770$ & $475-6215$ & $110-5754$ \\
\hline
\end{tabular}

LBW: Litter birth weight, LWW: Litter weaning weight, PLG: Pre-weaning litter gain. 
Table 3: Estimates of genetic parameters ( \pm standard error) for litter weight traits in APRI and V lines.

\begin{tabular}{cccc}
\hline & LBW & LWW & PLG \\
\hline APRI line & & & \\
$\mathrm{h}^{2}$ & $0.11 \pm 0.01$ & $0.10 \pm 0.01$ & $0.09 \pm 0.01$ \\
$\mathrm{r}$ & $0.31 \pm 0.03$ & $0.16 \pm 0.03$ & $0.15 \pm 0.03$ \\
$\sigma_{\mathrm{P}}^{2}$ & $8835 \pm 222$ & $435900 \pm 13077$ & $236299 \pm 8270$ \\
$\mathrm{~V}$ line & & & \\
$\mathrm{h}^{2}$ & $0.10 \pm 0.01$ & $0.09 \pm 0.01$ & $0.10 \pm 0.01$ \\
$\mathrm{r}$ & $0.31 \pm 0.01$ & $0.15 \pm 0.01$ & $0.16 \pm 0.02$ \\
$\sigma_{\mathrm{P}}^{2}$ & $5389 \pm 255$ & $309725 \pm 9992$ & $155957 \pm 6601$ \\
\hline
\end{tabular}

$\mathrm{h}^{2}$ : heritability, r: repeatability, $\sigma_{\mathrm{P}}^{2}$ : phenotypic variance, LBW: Litter birth weight, LWW: Litter weaning weight, PLG: Pre-weaning litter gain.

values of $\mathrm{p}^{2}$ in LBW rather than in the other traits could be attributed to the fact that LBW could be more influenced by prenatal maternal performance of the doe. The newly born kits seemed to be still affected by their mother's uterine environment. The present results confirm those of Lukefahr and Hamilton (1997), Rastogi et al. (2000), Al-Saef et al. (2008), Nofal et al. (2008) and Youssef et al. (2008b). The latter authors found that $\mathrm{h}^{2}$ estimates were higher than those of $\mathrm{p}^{2}$ for most of litter weight traits.

Low to moderate estimates of repeatability were observed for litter weight traits in the current study (Table 3). Ranges of values were 0.15 to 0.31 in both lines. The relatively higher estimate of repeatability for LBW in both lines is a result of the higher values of $\mathrm{p}^{2}$ in this trait compared with the other traits. Comparable results (0.09-0.21) were obtained by many authors (Lukefahr and Hamilton, 1997; Rastogi et al., 2000; Al-Saef et al., 2008; Nofal et al., 2008; Youssef et al., 2008b).

\section{Correlations}

Genetic and permanent environmental correlations among litter weight traits in both lines were generally high, especially between LWW and other traits (Table 4). This means that when selecting for LWW we also expect relatively important correlated responses in LBW and PLG.

Estimates of genetic correlations ranged from 0.77 to 0.97 and 0.80 to 0.94 in APRI and V lines, respectively. The current estimates seem to be somewhat higher than those obtained in Egyptian studies

Table 4: Estimates of genetic (above diagonal) and permanent environmental (below diagonal) correlations for litter weight traits ( \pm standard error) in APRI and V lines.

\begin{tabular}{cccc}
\hline & LBW & LWW & PLG \\
\hline APRI line & & & $0.77 \pm 0.20$ \\
LBW & - & $0.89 \pm 0.17$ & $0.97 \pm 0.18$ \\
LWW & $0.87 \pm 0.23$ & - & - \\
PLG & $0.47 \pm 0.17$ & $0.89 \pm 0.27$ & \\
V line & & & $0.85 \pm 0.21$ \\
LBW & - & $0.92 \pm 0.16$ & $0.94 \pm 0.14$ \\
LWW & $0.86 \pm 0.15$ & - & - \\
PLG & $0.65 \pm 0.14$ & $0.86 \pm 0.15$ & - \\
\hline
\end{tabular}

LBW: Litter birth weight, LWW: Litter weaning weight, PLG: Pre-weaning litter gain. 


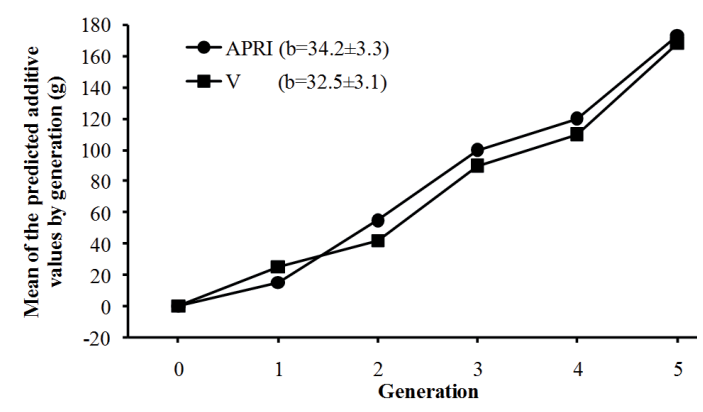

Figure 1: Genetic trend (b) of litter weaning weight in APRI and V lines.

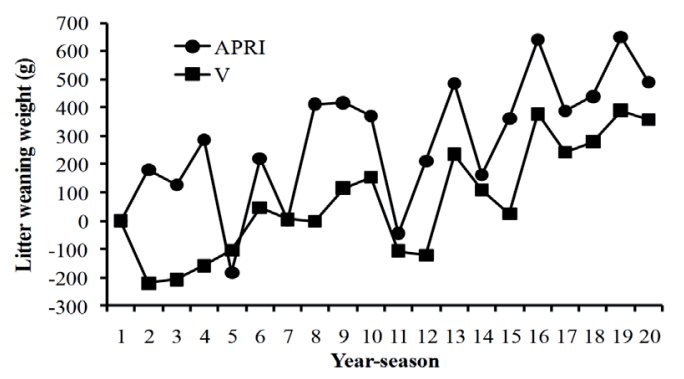

Figure 2: Year-season trend of litter weaning weight in APRI and V lines, starting from summer 2003 to spring 2008 .

by El-Feky et al. (2001), El-Deghadi (2005) and Gad (2007). These differences could be due to breed and environmental differences between the current experiment and the previous ones, as well as methods and models of analysis. The current high estimates of genetic correlation between LBW and LWW in both lines (around 0.9) could lead to the conclusion that most genes affecting litter birth weight may have an effect on the corresponding traits at later ages. Values of permanent environmental effect correlations were generally high but lower than genetic correlations. The ranges were 0.47 to 0.91 and 0.65 to 0.86 in APRI and V line rabbits, respectively.

\section{Genetic and environmental trends}

Few experimental results are so far available to estimate selection response or genetic trend for litter weight in rabbits using BLUP estimations. The genetic trend of LWW, calculated as the regression of the mean of the predicted additive values by generation on generation number is plotted in Figure 1. Similar genetic trends of LWW in APRI $(34.2 \pm 3.3 \mathrm{~g})$ and V $(32.5 \pm 3.1 \mathrm{~g})$ lines were found. Likewise, positive correlated genetic trends of LBW (5.7 \pm 0.6 and 6.1 $\pm 0.5 \mathrm{~g})$ and PLG (26.9 \pm 3.2 and 24.8 $\pm 3.1 \mathrm{~g})$ were observed in APRI and V lines, respectively. All regression coefficients were significant $(P<0.05)$. The current results are comparable to those obtained by Moura et al., (2001) and Bolet and Saleil (2002a), lower than those obtained by Bolet and Saleil (2002b) and Khalil et al. (2005). Differences in genetic trends throughout the experiments could be attributed to different populations and surrounding conditions.

Environmental changes in LWW largely reflected seasonal variations in production (Figure 2). Yearseason fluctuations were found in both lines. Generally, the dissimilarity among year-seasons in LWW could be attributed to the variation in climatic conditions.

\section{CONCLUSIONS}

Positive estimates of genetic trends in the present study indicate the expectations of success of the current breeding program, which should be continued and upgraded.

The high genetic correlations between litter weaning weight (as a selection criterion) and the other traits indicate that similar relative improvements could be expected in all traits.

Acknowledgments: The authors would like to thank the Spanish Agency of International Cooperation for supporting this work through the project "Sustainable production of rabbit meat: Evaluation and genetic improvement of Spanish-Egyptian rabbit lines". 


\section{REFERENCES}

Abou Khadiga G. 2004. Performance of the Spanish synthetic line V and the local Baladi Black rabbits and their crosses of rabbits and Egyptian conditions. M. Sc. Thesis, Faculty of Agriculture, Kafr ElSheikh, Tanta University, Egypt.

Al-Saef A.M., Khalil M.H., Al-Homidan A.H., Al-Dobaib S.N., AlSobayil K.A., García M.L, Baselga M. 2008. Crossbreeding effects for litter and lactation traits in a Saudi project to develop new lines of rabbits suitable for hot climates. Livest. Sci., 118: 238-246.

Baselga M. 2004. Genetic improvement of meat rabbits. Programmes and diffusion. In Proc.: $8^{\text {th }}$ World Rabbit Congress, 7-10 September, 2004. Puebla, Mexico. 1-13.

Bolet G., Saleil G. 2002a. Strain INRA1077. In: Khalil M.H., Baselga M. (Eds.). Rabbit genetic resources in Mediterranean countries. Options méditerranéennes, B: Etudes et recherches. CIHEAM, Zaragoza, Spain. 38: 109-116.

Bolet G., Saleil G. 2002b. Strain INRA2066. In: Khalil M.H., Baselga M. (Eds.). Rabbit genetic resources in Mediterranean countries. Options méditerranéennes, B: Etudes et recherches, Numéro 38, CIHEAM, Zaragoza, Spain, 117-124.

Costa C., Baselga M., Lobera J., Cervera C., Pascual J.J. 2004 Evaluating response to selection and nutritional needs in a threeway cross of rabbits. J. Anim. Breed. Genet., 121: 186-196.

El-Deghadi 2005. Genetic evaluation for some productive traits in rabbits. Ph. D. Thesis, Faculty of Agriculture, Banha University, Egypt.

El-Feky F.A., Aboul-Hassan M.A., Attalah G.E., Bata S.S. 2001 Selection indices for improving body weight in Baladi Red rabbit. Egypt. Poult. Sci., 21: 305-318.

Estany J., Baselga M., Blasco A., Camacho J. 1989. Mixed model methodology for the estimation of genetic response to selection in litter size of rabbits. Livest. Prod. Sci., 21: 67-76.

Gad S.M. 2007. Genetic analysis for productivity of Gabali rabbits raised in the north-western coast of Egypt. Ph. D. Thesis, Fac. Agriculture, Moshtohor, Banha University, Egypt.

Gómez E.A., Rafel O., Ramón J., Baselga M. 1996. A genetic study of a line selected on litter size at weaning. In Proc.: $6^{\text {th }}$ World Rabbit Congress, 9-12 July, 1996. Toulouse. France. Vol. 2, 289-292.

Gómez E.A., Rafel O., Ramón J. 2000. Preliminary genetic analysis of Caldes line: a selection experiment for a global objective. In Proc.: $7^{\text {th }}$ World Rabbit Congress, 4-7 July, 2000, Valencia, Spain. Vol.A, $417-424$

Henderson C.R. 1973. Sire evaluation and genetic trends. In Proc.: The Animal Breeding and Genetics Symposium In honour of Dr. J. L. Lush in Blacksburg. Virginia. ASAS and ADSA, 10-41.

Iraqi M.M., Ibrahim M.K., Hassan N.S.H., El-Deghadi A.S. 2006. Evaluation of litter traits in purebred and crossbred rabbits raised under Egyptian conditions. Livest. Res. Rural. Dev., 18. No. 83. Available at: http://www.lrrd.org/lrrd18/6/iraq18083.htm

Khalil M.H., García M.L., Al-Dobaib S.N., AL-Homidan A.H., Baselga M. 2005. Genetic evaluation of crossbreeding project involving Saudi and Spanish V-line rabbits to synthesize new maternal lines in Saudi Arabia: I. Pre-weaning litter, lactation traits and feeding parameters. In: Proc. $4^{\text {th }}$ International Conference of Rabbit Production in Hot Climate, 2005 February, Sharm El-Sheikh, Egypt, 89-99.
Lukefahr S.D., Hamilton H.H. 1997. Heritability and repeatability estimates of maternal performance traits in purebred and crossbred does. World Rabbit Sci., 5: 99-105.

Meyer K. 2006. WOMBAT - A program for mixed model analyses by restricted maximum likelihood. User notes. Animal Genetics and Breeding Unit, Armidale, $83 \mathrm{pp}$.

Moura A.S.A.M.T., Costa A.R.C., Polastre R. 2001. Variance components and response to selection for reproductive litter and growth traits through a multi-purpose index. World Rabbit Sci., 9: 77-86.

Nofal R., Hassan N., Abdel-Ghany A., Gyorgyi V. 2008. Estimation of genetic parameters for litter size and weight traits in NZW rabbits raised in Hungary. In Proc.: $9^{\text {th }}$ World Rabbit Congress, 10-13 June, 2008. Verona, Italy. 185-188.

Quaas R.L. 1984. Linear Prediction. BLUP School Handbook. Anim. Genet. Proced. Unit., University of New England, Australia, pp. $1-76$.

Rastogi R.K., Lukefahr S.D., Lauckner F.B. 2000. Maternal heritability and repeatability for litter traits in rabbits in a humid tropical environment. Livest. Prod. Sci., 67: 123-128.

Rochambeau H. de., Duzert R., Tudela F. 1998. Long term selection experiments in rabbit. Estimation of genetic progress on litter size at weaning. In Proc.: $6^{\text {th }}$ World Congress on Genetics Applied to Livestock Production, Armidale, NSW, Australia, 11-16 January 1998, Vol., 26: 112-115.

Salaun J.M., Garreau H., thebault R.G., Allain D., Rochambeau H. de. 2001. Sélection pour le poids total de lapereaux par femelle et par an dans une souche de lapins Castor Rex. In Proc.: $9^{\text {èmes }}$ Journées de la Recherche Cunicole, November, 2001. Paris, France. 221-224.

Sorensen D.A., Johanson K. 1992. Estimation of direct and correlated responses to selection using univariate animal models. J. Anim. Sci., 70: 2038-2044.

Sorensen D.A., Kennedy B. W. 1984. Estimation of response to selection using least squares and mixed model methodology. $J$. Anim. Sci., 85: 1097-1106.

Youssef Y.K., Iraqi M.M., El-Raffa A.M., Afifi E.A., Khalil M.H., García M.L., Baselga M. 2008a. A joint project to synthesize new lines of rabbits in Egypt and Saudi Arabia: emphasis for results and prospects. In Proc.: th $^{\text {th }}$ World Rabbit Congress, 10-13 June, 2008. Verona, Italy. 1637-1642.

Youssef Y.M. K., Baselga M., Khalil M.H., Gad-Alla S., García M.L. 2008b. Evaluation of litter traits in a crossing project of Spanish V-line and Baladi Red rabbits in Egypt. Livest. Res. Rural. Dev., 20. No. 135. Available at: http://www.lrrd.org/lrrd20/9/yous20135.htm 